\title{
Initiation of transform faults at rifted continental margins 3D petrological-thermomechanical modeling and comparison to the Woodlark Basin
}

\author{
Journal Article \\ Author(s): \\ Gerya, Taras \\ Publication date: \\ 2013 \\ Permanent link: \\ https://doi.org/10.3929/ethz-b-000074990 \\ Rights / license: \\ In Copyright - Non-Commercial Use Permitted \\ Originally published in: \\ Petrology 21(6), https://doi.org/10.1134/S0869591113060039
}




\title{
Initiation of Transform Faults at Rifted Continental Margins: 3D Petrological-Thermomechanical Modeling and Comparison to the Woodlark Basin ${ }^{1}$
}

\author{
T. V. Gerya \\ Institute of Geophysics, ETH Zürich, Sonneggstrasse 5, 8092 Zürich, Switzerland \\ e-mail: taras.gerya@erdw.ethz.ch \\ Received January 22, 2013; in final form, April 3, 2013
}

\begin{abstract}
This work presents high-resolution 3D numerical model of transform fault initiation at rifted continental margins. Our petrological-thermomechanical visco-plastic model allows for spontaneous nucleation of oceanic spreading process in a continental rift zone and takes into account new oceanic crust growth driven by decompression melting of the asthenospheric mantle. Numerical model predicts that ridge-transform spreading pattern initiate in several subsequent stages: crustal rifting (0-1.5 Myr), spreading centers nucleation and propagation (1.5-3 Myr), proto-transform fault initiation and rotation (3-5 Myr) and mature ridge-transform spreading (>5 Myr). Comparison of modeling results with the natural data from the Woodlark Basin suggests that the development of this region closely matches numerical predictions. Similarly to the model, the Moresby (proto-) Transform terminates in the oceanic rather than in the continental crust. This fault associates with a notable topographic depression and formed within 0.5-2 Myr while linking two offset overlapping spreading segments. Model reproduces well characteristic "rounded" contours of the spreading centers as well as the presence of a remnant of the broken continental crustal bridge observed in the Woodlark Basin. Proto-transform fault traces and truncated tip of one spreading center present in the model are also documented in nature. Numerical results are in good agreement with the concept of Taylor et al. (2009) which suggests that spreading segments nucleate en echelon in overlapping rift basins and that transform faults develop as or after spreading nucleates. Our experiments also allow to refine this concept in that (proto)-transform faults may also initiate as oblique rather than only spreading-parallel tectonic features. Subsequent rotation of these faults toward the extension-parallel direction is governed by space accommodation during continued oceanic crust growth within offset ridge-transform intersections.
\end{abstract}

DOI: $10.1134 / \mathrm{S} 0869591113060039$

\section{INTRODUCTION}

Origin and dynamics of oceanic transform faults initiation remains a matter of debates (e.g., Gerya, 2012 and references therein). One common view is that oceanic transform faults are inherited from the continental plate breakup (e.g., Wilson, 1965; Lister et al., 1986; Cochran and Martinez, 1988; McClay and Khalil, 1998; Behn and Lin, 2000). However, an alternative view exists (Bosworth, 1986; Rosendahl, 1987; Taylor et al., 1995, 2009) that the characteristic orthogonal ridge-transform fault pattern is not directly inherited from the earlier rift geometry. This view is, in particular, supported by recent high-resolution bathymetry data from the incipient oceanic spreading regions such as Woodlark Basin, Gulf of Aden and NW Australia showing that initial offsets between oceanic spreading centers, where present, are typically nontransform (Taylor et al., 1995, 2009).

Due to the limited availability of natural data, detailed interpretations of nucleation and evolution of

\footnotetext{
${ }^{1}$ The article is published in the original.
}

ridge-transform oceanic spreading patterns are difficult and controversial (e.g., Lister et al., 1986; Bosworth, 1986; Taylor et al., 1995, 2009). In addition to natural studies, a number of analogue and numerical models of rifting and spreading have been developed and investigated (see recent review by Gerya, 2012 and references therein). Analogue models comprised (i) themomechanical freezing wax models with accreting and cooling plates (Oldenburg and Brune, 1972; O’Bryan, et al., 1975; Ragnarsson et al., 1996; Katz et al., 2005) and (ii) purelly mechanical models with brittle lithosphere and viscous mantle (Dauteuil and Brun, 1993; Dauteuil et al., 2002; Marques et al., 2007; Tentler and Acocella, 2010). Both types of models are proven to be useful for analyzing physics and dynamics of spreading process but have certain dissimilarities to nature (Gerya, 2012, 2013 and references therein): the freezing wax models often produced open spreading centers with exposed liquid wax, whereas new lithosphere is not accreted in purely mechanical models. Due to the growing computational power numerical models of oceanic spreading have recently become increasingly popular (Gerya, 


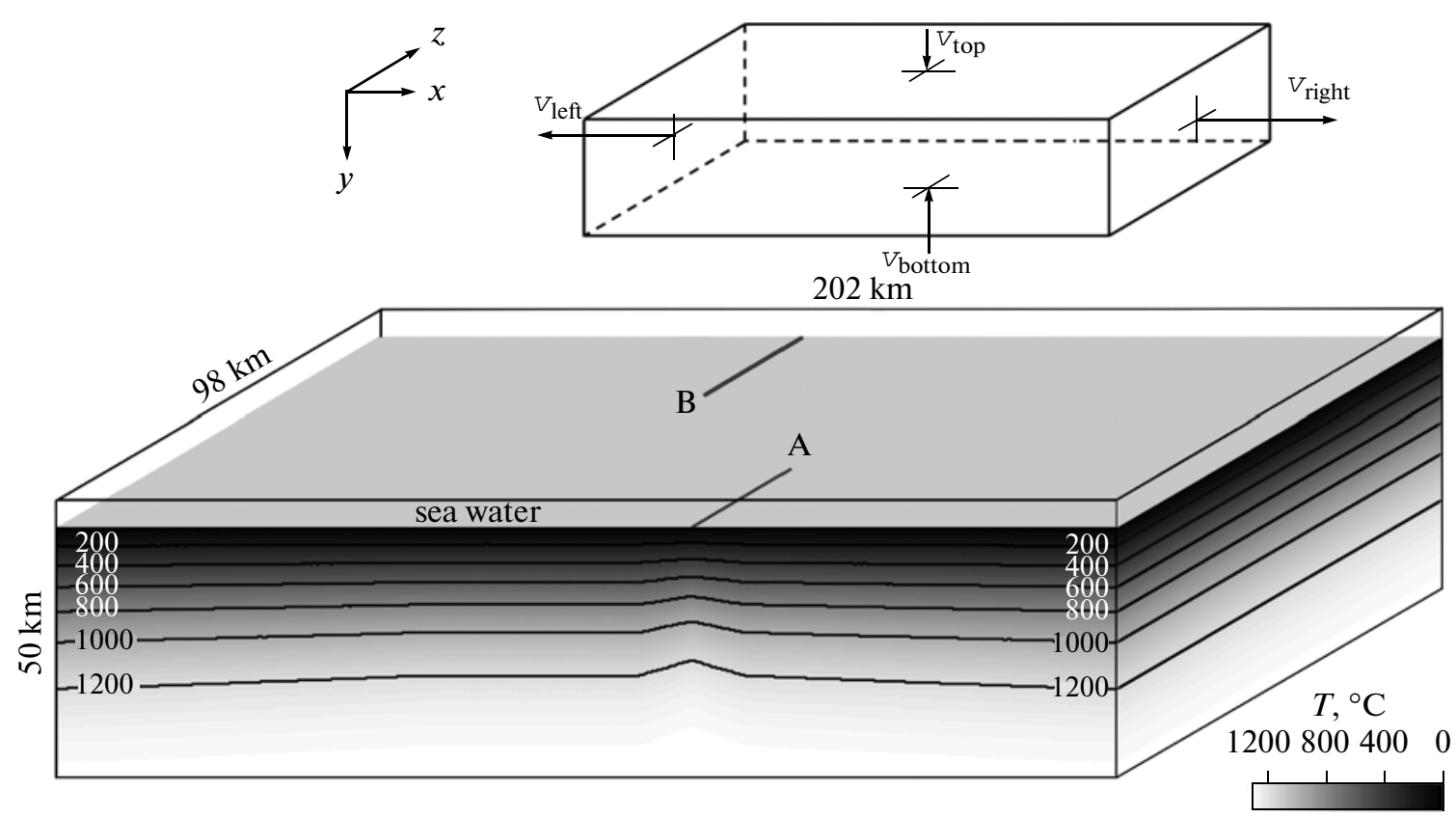

Fig. 1. Initial model setup and boundary conditions for 3D petrological-thermomechanical numerical model. Boundary conditions are constant spreading rate in $x$-direction ( $v_{\text {spreading }}=v_{\text {left }}+v_{\text {right }}$, where $\left.v_{\text {left }}=v_{\text {right }}\right)$ and compensating vertical influx velocities through the upper and lower boundaries $\left(v_{\text {top }}\right.$ and $\left.v_{\text {bottom }}\right)$ are chosen to ensure conservation of volume of the model domain and constant average $5 \mathrm{~km}$ thickness of the sea water layer $\left[\left(v_{\text {top }}+v_{\text {bottom }}\right) / 50=\left(v_{\text {left }}+v_{\text {right }}\right) / 202\right)$, where $v_{\text {top }} / 5=$ $\left.V_{\text {bottom }} / 45\right]$; front and back boundaries in the $x-y$ plane are free slip. A water-loaded free surface condition for the upper plate boundary is implemented by using a weak layer approach (e.g., Schmeling et al., 2008; Gerya, 2010b; Crameri et al., 2012): the weak $5 \mathrm{~km}$ thick sea water layer has a characteristic density of $1000 \mathrm{~kg} / \mathrm{m}^{3}$ and a viscosity of $10^{18}$ Pa s to ensure small stresses $\left(<10^{5} \mathrm{~Pa}\right)$ along the upper plate interface. The symmetric initial thermal structure is perturbed in two places where offset linear thermal anomalies (weak seeds) A and B are prescribed by gently elevated geotherm. Thermal boundary conditions are insulating (zero heat flux) on all boundaries with except of the upper and lower boundaries, over which a constant temperature of $0^{\circ} \mathrm{C}$ and $1330^{\circ} \mathrm{C}$ is prescribed, respectively.

2012 and references therein). Initially, numerical models of oceanic spreading (Hieronimus, 2004; Choi et al., 2008) and continental rifting (Allken, et al., $2011,2012)$ patterns focused on relatively short-term plate fragmentation (rifting) processes and demonstrated that various ridge-transform linkage patterns can spontaneously arise from small, initially offset perturbations (weak seeds) in the plate structure. More recent large-strain numerical thermomechanical experiments (Gerya, 2010a, 2013) analyzed spontaneous nucleation and long-term evolution of ridgetransform oceanic spreading patterns. Both analogue and numerical models addressed important aspects of oceanic spreading physics and dynamics (Gerya, 2012 and references therein) but detailed comparison of their predictions with natural data from the incipient oceanic spreading regions remains challenging and requires further effort.

In the present paper, we build on the results of previous numerical experiments (Gerya, 2013) to investigate high-resolution 3D thermomechanical numerical model of incipient oceanic spreading and compare it to observations from the Woodlark Basin. The principal goal of this study is to try to understand detailed dynamics of incipient spreading process and resolve existing controversies for initiation and evolution of ridge-transform oceanic spreading patterns (Lister et al., 1986; Bosworth, 1986; Taylor et al., 1995, 2009).

\section{NUMERICAL MODEL}

We use high-resolution 3D petrological-thermomechanical numerical model of an incipient oceanic spreading developed in our previous work (Gerya, 2013). The Eulerian-Lagrangian visco-plastic model with an internal free surface (Fig.1) allows for large degree of plate separation and spontaneous oceanic crust growth by magmatic accretion. Parametric study for this model is presented by Gerya (2013) who investigated its sensitivity to various physical parameters.

The initial model setup corresponds to the onset of oceanic spreading within an already extended (rifted) thin and hot continental lithosphere. In this idealized lithosphere, continental crustal thickness is reduced to $20 \mathrm{~km}$ and a geothermal gradient is strongly elevated. In order to initiate offset spreading centers, two linear thermal perturbations (see perturbations $\mathrm{A}$ and $\mathrm{B}$ in Fig. 1) with an offset of $50 \mathrm{~km}$ are imposed at the bottom of the lithospheric mantle (Fig. 1). In order to make model development slightly asymmetric as in 


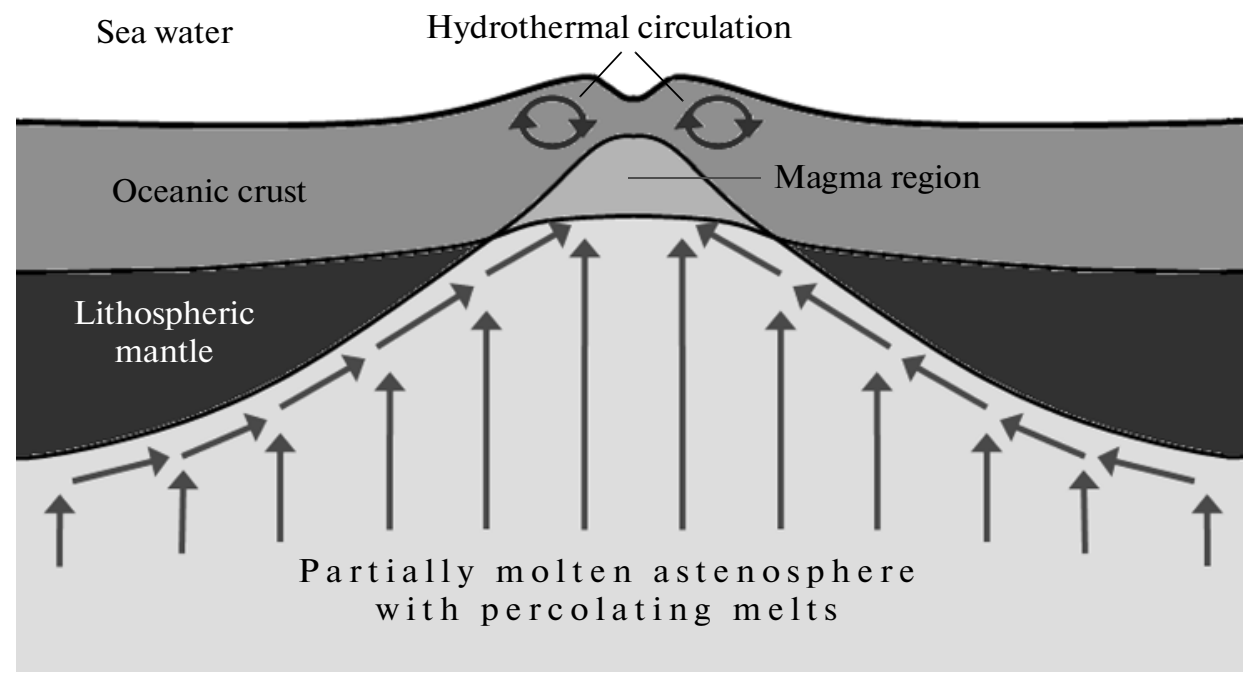

Fig. 2. Conceptual model of oceanic spreading (Gerya, 2013) used in this study. See text for more details.

the Woodlark Basin, where spreading initiates early in the East than in the West (Taylor et al., 2009), thermal magnitude of the frontal perturbation (see perturbation A in Fig. 2) is taken to be smaller than the magnitude of the rear one (see perturbation B in Fig. 2). The magnitude of the imposed offset between the perturbations compares well with observations in the Woodlark Basin (as well as in the other incipient spreading regions) where these offsets are typically in the range of several tens of kilometers (e.g., Bosworth, 1986; Taylor et al., 1995, 2009). The modeled (full) spreading rate $\left(v_{\text {spreading }}\right)$ is $3.8 \mathrm{~cm} / \mathrm{yr}$, which simulates incipient slow- to intermediate-spreading ridge such as in the Woodlark Basin (Taylor et al., 2009). The Eulerian model domain is equivalent to $202 \times 98 \times 50 \mathrm{~km}$ (Fig. 1) and is resolved with a regular rectangular grid of $405 \times 197 \times 101$ nodes and contains 68 million randomly distributed Lagrangian markers. The EulerianLagrangian numerical modeling scheme with open boundaries (Gerya, 2010a, 2013) allows for an infinitely long plate separation. Lagrangian markers leave the Eulerian model domain through the left and right lateral boundaries and enter through the top and the bottom of the model as sea water and asthenospheric mantle markers, respectively. The initial thermal structure of the model with $1000^{\circ} \mathrm{C}$ isotherm located at the depth of $21 \mathrm{~km}$ is shown in Fig. 1. Asthenospheric mantle temperature is set to $1330^{\circ} \mathrm{C}$.

Figure 2 shows a conceptual scheme of numerical model design (Gerya, 2013) used in the present study. It accounts for the following key processes which were suggested to be critical for realistic modeling of plate breakup and oceanic spreading (e.g., Buck et al., 2005; Gregg et al., 2009; Katz, 2010; Olive et al., 2010; Theissen-Krah et al., 2011; Montesi et al., 2011): (i) thermal accretion of the oceanic mantle lithosphere resulting in the plate thickness growth, (ii) par- tial melting of the asthenospheric mantle, melt extraction and percolation toward the ridge resulting in crustal growth, (iii) magmatic accretion of the new oceanic crust under the ridge and (iv) hydrothermal circulation at the axis of the ridge, resulting in excess cooling of the crust. Below we explain in short how each process was introduced in the model (see (Gerya, 2013) for more details and discussions).

Thermal accretion of the mantle lithosphere is modeled by solving the heat conduction equation combined with a temperature-dependent viscosity for the non-molten mantle (dry olivine flow law, Ranalli, 1995). Consequently, cooling of asthenospheric mantle become rheologically strong and accretes spontaneously to the bottom of the oceanic lithosphere. Mantle density depends on pressure and temperature and is computed as

$$
\rho=\rho_{0}[1-\alpha(T-298)][1+\beta(P-0.1)],
$$

where $k_{0}=3300 \mathrm{~kg} / \mathrm{m}^{3}$ is the standard mantle density, $\alpha=3 \times 10^{-5} 1 / \mathrm{K}$ and $\beta=10^{-5} 1 / \mathrm{MPa}$ are thermal expansion and compressibility of the mantle.

Hydrothermal circulation at the axis of the ridge producing rapid cooling of the new oceanic crust (e.g., Theissen-Krah et al., 2011) is parameterized with an enhanced thermal conductivity of the crust based on the following equation (Gregg et al., 2009)

$$
k_{\text {eff }}=k+k_{0}(N u-1) \exp \left[\mathrm{A}\left(2-T / T_{\max }-y / y_{\max }\right)\right] \text {, }
$$

where $T$ is the temperature $\left({ }^{\circ} \mathrm{C}\right) k$ is the thermal conductivity of dry rocks $(\mathrm{W} / \mathrm{m} / \mathrm{K})[k=0.73+1293 /(T+77)$ for the mantle and $k=1.18+474 /(T+77)$ for the crust (Clauser and Huenges, 1995)], $k_{0}=3 \mathrm{~W} / \mathrm{m} / \mathrm{K}$ is the reference thermal conductivity, $N u=2$ is the assumed Nusselt number for the hydrothermal circulation (Gregg et al., 2009), $A=0.75$ is a smoothing factor, $T_{\max }$ is the cutoff maximum temperature 
$\left(600^{\circ} \mathrm{C}\right), y$ is depth $(\mathrm{km})$, and $y_{\max }=6 \mathrm{~km}$ is the cutoff maximum depth of hydrothermal circulation.

Partial melting of the asthenospheric mantle, melt extraction and percolation toward the ridge is parameterized in a simplified manner: crustal growth at the ridge is balanced by the melt production and extraction in the mantle. Lagrangian mantle markers track the amount of melt extracted during the evolution of each experiment. The total amount of melt, $M$, for every marker is calculated as (Gerya, 2013)

$$
M=M_{0}-\Sigma_{n} M_{\mathrm{ext}},
$$

where $M_{0}$ is the standard (i.e. without melt extraction) volumetric degree of mantle melting computed with the batch melting model (Katz et al., 2003), $\Sigma_{n} M_{\text {ext }}$ is the total melt fraction extracted during the previous $n$ extraction episodes. The rock is considered non-molten (refractory) when the extracted melt fraction is larger than the standard one (i.e. when $\Sigma_{n} M_{\text {ext }}>M_{0}$ ). If $M>0$ for a given marker, the melt fraction $M_{\text {ext }}=M$ is extracted and $\Sigma_{n} M_{\text {ext }}$ is updated. Melts extracted in the entire model are added evenly to the top of the shallowest partially molten mantle regions. These regions are typically located beneath the ridge axis and inside intra-transform spreading centers where wedgeshaped magma regions (Fig. 2) spontaneously form by accumulation of the introduced melts. Size and shape of the magma chambers form spontaneously and is regulated by the dynamics of melt supply from the bottom, crustal extension at the top and magma crystallization in response to cooling from the walls. No flow field divergence is created in response to melt accretion to the bottom of the magma chambers. Additional space for the melt is assumed to be created by viscous compaction and subsidence of the melt-bearing mantle. In order to ensure melt volume conservation and account (indirectly) for the mantle compaction and subsidence in response to the melt extraction, melt addition to the bottom of the magma region is performed at every time step by converting shallowest markers of hot partially molten mantle into magma markers. The total volume of these magma markers matches the total volume of extracted melt computed for the time step. It should be noted, that complex internal dynamics and structure of the magma region (e.g., deep melt pooling, mush zone, shallow melt lens, diking, Wanless and Shaw, 2012) is not reproduced in our simple model, which does not account for crystal differentiation and melt percolation processes inside these regions.

Magmatic accretion of the new oceanic crust is modeled by spontaneous cooling and crystallization of melts at the walls of the lower-crustal magma region (e.g., Wanless and Shaw, 2012). Local melt fraction $M$ in this region is computed from the simple linear melting model (Gerya, 2010b)

$$
\begin{gathered}
M=0, \text { when } T<T_{\text {solidus }}, \\
M=\left(T-T_{\text {solidus }}\right) /\left(T_{\text {liquidus }}-T_{\text {solidus }}\right), \\
\text { when } T_{\text {solidus }}<T<T_{\text {liquidus }}, \\
M=1, \text { when } T>T_{\text {liquidus }},
\end{gathered}
$$

where $T_{\text {solidus }}=1327+0.091 P$ and $T_{\text {liquidus }}=1423+$ $0.105 P$ are, respectively, solidus and liquidus temperature (K) of the crust (Hess, 1989) at a given pressure $P$ (MPa). The effective density of the crystallizing crust is calculated as

$$
\rho_{\text {eff }}=\rho_{\text {solid }}\left(1-M+M \frac{\rho_{0 \text { molten }}}{\rho_{0 \text { solid }}}\right)
$$

where $\rho_{0 \text { solid }}=3000 \mathrm{~kg} / \mathrm{m}^{3}$ and $\rho_{0 \text { solid }}=2800 \mathrm{~kg} / \mathrm{m}^{3}$ are the standard densities of solid and molten crust, respectively and $\rho_{\text {solid }}$ is the density of solid crust at given $P$ and $T$ computed from equation (1) with $\rho_{0}=\rho_{0 \text { solid }}, \alpha=3 \times 10^{-5} 1 / \mathrm{K}$ and $\beta=10^{-5} 1 / \mathrm{MPa}$.

The rheological model used in this study assumes a constant low viscosity ( $\left.10^{18} \mathrm{~Pa} \mathrm{~s}\right)$ for the partially molten crustal and mantle rocks, and a visco-plastic rheology for the lithospheric plates, with a realistic temperature and strain rate dependent viscosity computed according to experimentally determined flow laws (Ranalli, 1995). We use the dry olivine flow law for the mantle and the plagioclase $\left(A n_{75}\right)$ flow law for the crust. An upper viscosity cutoff limit of $10^{24} \mathrm{~Pa} \mathrm{~s}$ was applied for the lithospheric viscosity. Brittle/plastic rheology of solid rocks assumes fracture-related strain weakening and healing (Lavier et al., 2000; Huismans and Beaumont, 2002; Hieronimus, 2004; Choi et al., 2008; Gerya, 2010a, 2013; Allken et al., 2011, 2012)

$$
\begin{gathered}
\sigma_{\mathrm{II}} \leq C_{\gamma}+\phi_{\gamma}\left(P-P_{f}\right) \\
\left.\phi_{\gamma}=1, \text { when } P<P_{f} \text { (tensile fracture }\right) \\
\phi_{\gamma}=0.6\left(1-\gamma / \gamma_{0}\right) \text { for } \gamma \leq \gamma_{0} \text { and } \phi_{\gamma}=0 \text { for } \gamma>\gamma_{0} \\
\text { when } P \geq P_{f}(\text { confined fracture }) \\
C_{\gamma}=C_{0}+\left(C_{1}-C_{0}\right) \gamma / \gamma_{0} \text { for } \gamma \leq \gamma_{0} \text { and } C_{\gamma}=C_{1} \text { for } \gamma>\gamma_{0},(8) \\
P_{f}=\rho_{f} g y \\
\gamma=\int \sqrt{\frac{1}{2}\left(\dot{\varepsilon}_{i j(\text { plastic })}\right)^{2}} d t-\int \dot{\varepsilon}_{\text {healing }} d t \\
\sigma_{\mathrm{II}}=\sqrt{\frac{1}{2}\left(\sigma_{i j}^{\prime}\right)^{2}}
\end{gathered}
$$

where $\sigma_{\mathrm{II}}$ is second stress invariant $(\mathrm{Pa}), P$ is dynamic pressure on solids $(\mathrm{Pa}), P_{f}$ is fluid pressure $(\mathrm{Pa}), y$ is vertical coordinate $(\mathrm{m}), g=9.81 \mathrm{~m} / \mathrm{s}^{2}$ is gravitational acceleration, $\rho_{f}=1000 \mathrm{~kg} / \mathrm{m}^{3}$ is water density, $\gamma \geq 0$ is 

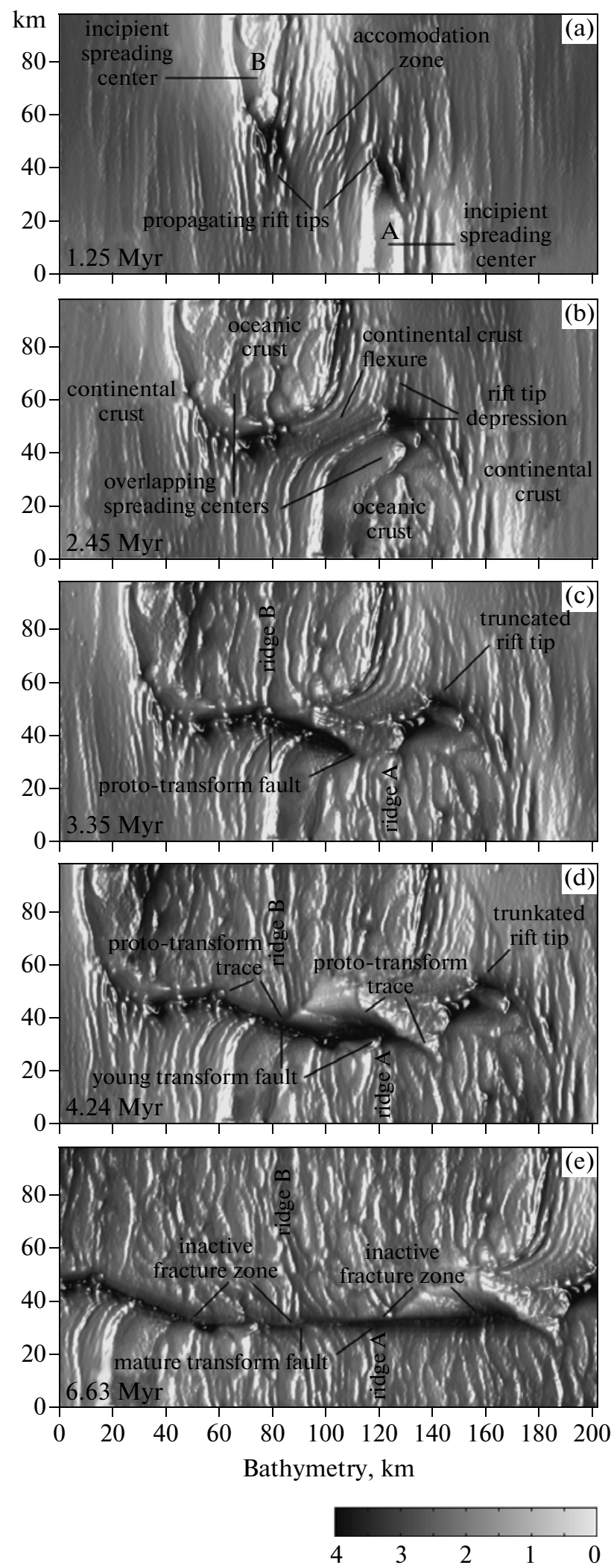

Fig. 3. Development of the model topography with time. Sea level for bathymetry maps corresponds to the top of the model. Strips on the surface of new oceanic crust correspond to normal fault scarps. integrated plastic strain ( $\gamma_{0}=1$ is the upper strain limit for the fracture-related weakening), $t$ is time (s), $\dot{\varepsilon}_{i j \text { (plastic) }}$ is plastic strain rate tensor, $\dot{\varepsilon}_{\text {healing }}=10^{-13} \mathrm{~s}^{-1}$ is fracture healing rate (Gerya, 2013), $C_{\gamma}$ is the rock strength at $P-P_{f}=0$ (for both confined and tensile fracture) which depends on the plastic strain $\gamma$ and $C_{0}=20 \mathrm{MPa}$ and $C_{1}=3 \mathrm{MPa}$ are the initial and final strength values for the fracture-related weakening, respectively.

\section{NUMERICAL MODEL DEVELOPMENT}

Figures 3-6 show evolution of the numerical model associated with the spontaneous development of offset oceanic spreading centers evolving into the typical orthogonal ridge-transform spreading pattern. At the initial stages (0-1.5 Myr, Figs. 3a, 4a, 5a, 6a), continental crust undergo local extension (necking) and two offset rifts form above the imposed thermal perturbations A and B. Two offset incipient spreading centers nucleate inside the rifts, which propagate toward each other. Triangular topographic depressions (rift tips, Fig. 3a) form in front of the propagating spreading centers. Due to the larger magnitude of the initial thermal perturbation B, respective spreading center develops more rapidly and propagates faster (Figs. 3a, 4a, 5a, 6a). An accommodation zone (Bosworth, 1986; Jarrige et al., 1990) with intense faulting pattern forms between the spreading centers (Figs. 3a, 4a). Extensional deformation inside the spreading centers is accommodated by large offset normal faults (detachment faults, Fig. 6a). Triangular shaped magma regions develop under the spreading centers as the result of lithospheric necking and associated decompression melting of rising hot asthenosphere (Fig. 6a). At the next stage (1.5-3 Myr, Figs. 3b, 4b, $5 \mathrm{~b}, 6 \mathrm{~b})$ spreading centers overlap and begin to widen. The accommodation zone becomes strongly deformed (crustal flexure, Fig. 3b) taking form of an elongated continental crust bridge (Figs. 3b, 5b) that divides two widening spreading centers. Further deformation of the crustal bridge is manifested by the onset at 33.5 Myr (Figs. 3c, 4c) of a strike-slip proto-transform fault (Gerya, 2013) which is striking at around $25^{\circ}$ to the extension direction. A 5-7 km wide and $1-3 \mathrm{~km}$ deep, elongated depression forms above this fault (Fig. 3c). The development of the proto-transform fault breaks the crustal bridge, thus forming two separate plates, and truncates propagation of the spreading centers. Truncated tip of the spreading center A leaves clear topographic and crustal signature on the right plate (Figs. 3c, 5c). Major fragment of the broken crustal bridge is also accreted to the this plate (Figs. 5d-5e). Next stage (3.5-5 Myr, Figs. 3d, 4d, 5d, $6 \mathrm{~d})$ is manifested by gradual rotation of the prototransform fault toward an extension-parallel direction. As explained in the previous paper (Gerya, 2013), an ongoing crustal growth and sustaining weakness of the fault (e.g., Oldenburg and Brune, 1972; Behn et al., 

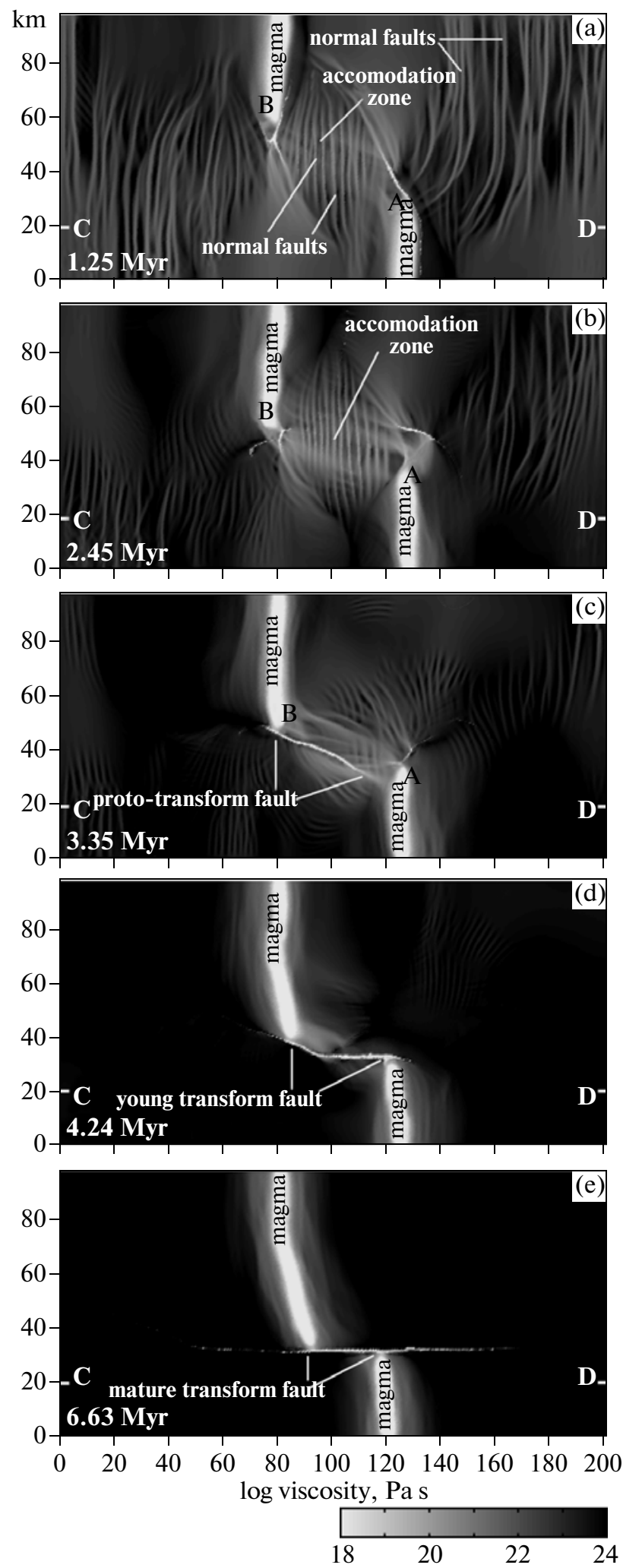

Fig. 4. Development of the effective viscosity field for the model with time. Horizontal cross-section for viscosity field is taken at the level of $10 \mathrm{~km}$ from the top of the model. Letters $\mathrm{C}$ and $\mathrm{D}$ mark positions of vertical cross-sections shown in Fig. 6. Model stages correspond to Fig. 3.
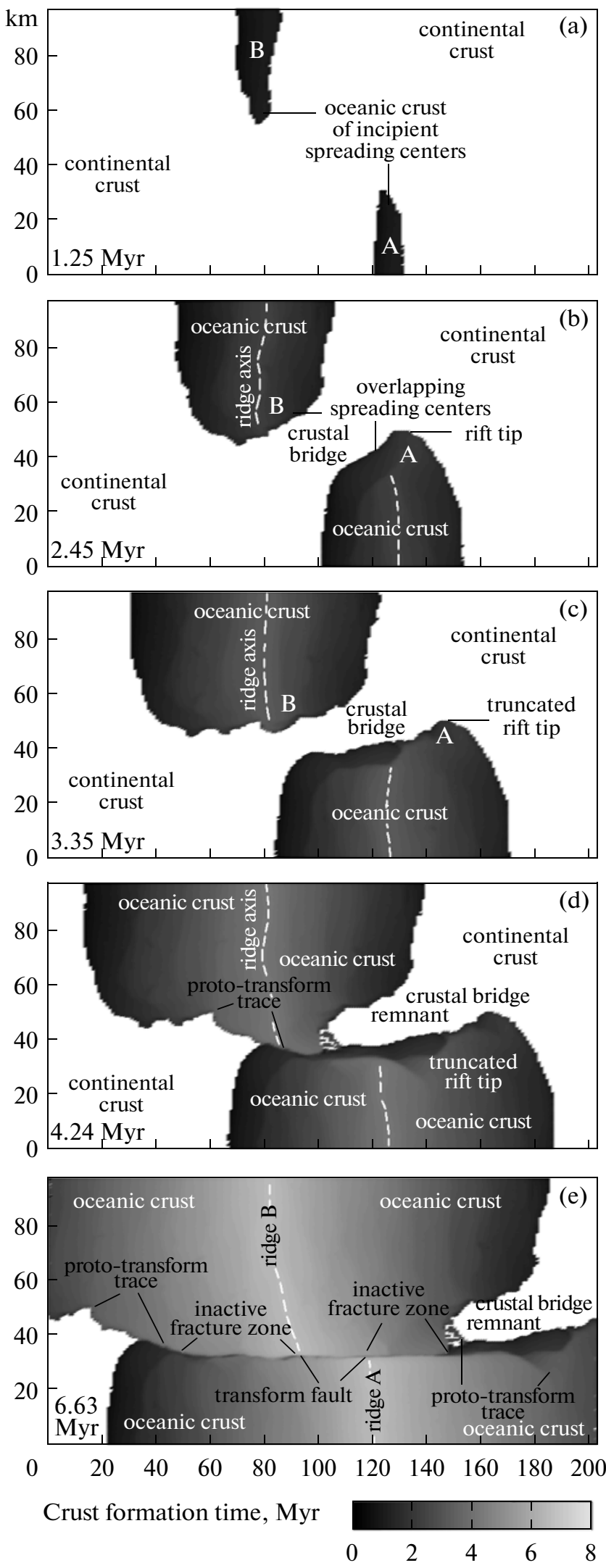

Fig. 5. Crust formation time pattern at the model surface. The formation time corresponds to the moment of crust crystallization from the melt. Model stages correspond to Fig. 3. 

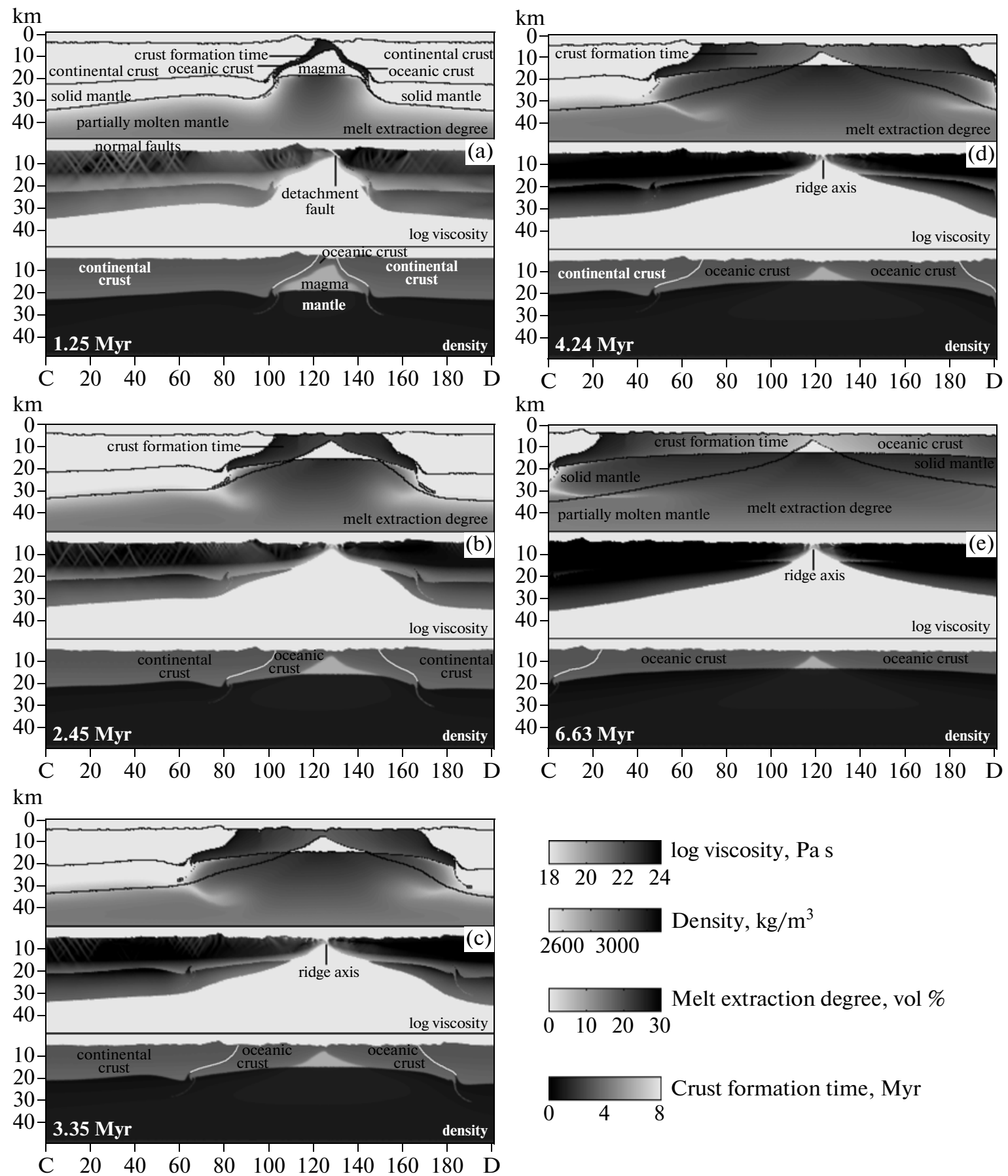

Fig. 6. Distribution of the oceanic crust formation time, melt extraction degree from the mantle, effective viscosity and density of rocks for the vertical cross-sections C-D shown in Fig. 4. Model stages correspond to Fig. 3.

2002) cause the rotation. This is because deformation within the proto-transform fault striking at an angle to the spreading direction is transtensional. The extensional component causes gradual opening of the fault associated with propagation of magma regions toward its rigid walls and accretion of the new oceanic crust at the two ridge-fault intersections (Figs. 5c-5d). Due to the sustaining weakness of the fault, the connection between the propagating tips of the spreading centers is continuously re-established which causes rotation of the fault toward the spreading-parallel direction. Stable extension-parallel orientation of the fault is established at ca. $5 \mathrm{Myr}$, which stops its further opening and rotation. The remaining model development 
154
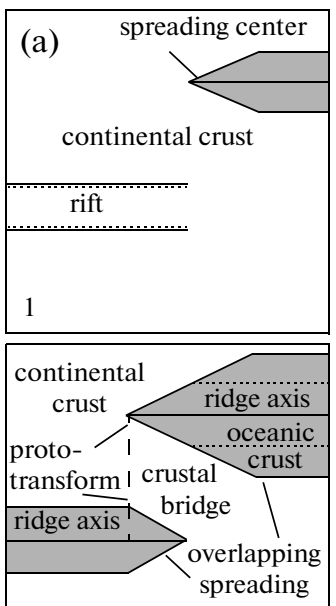

continental centers

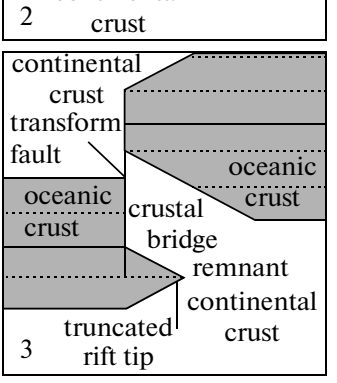

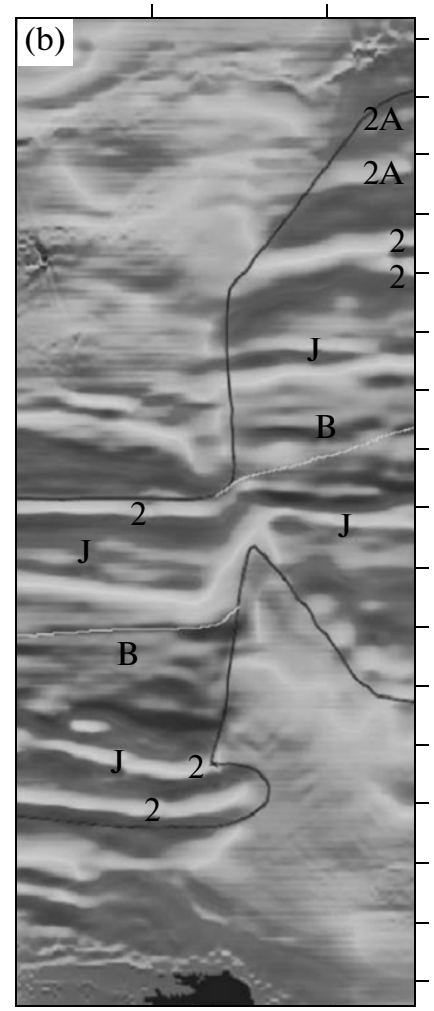

154

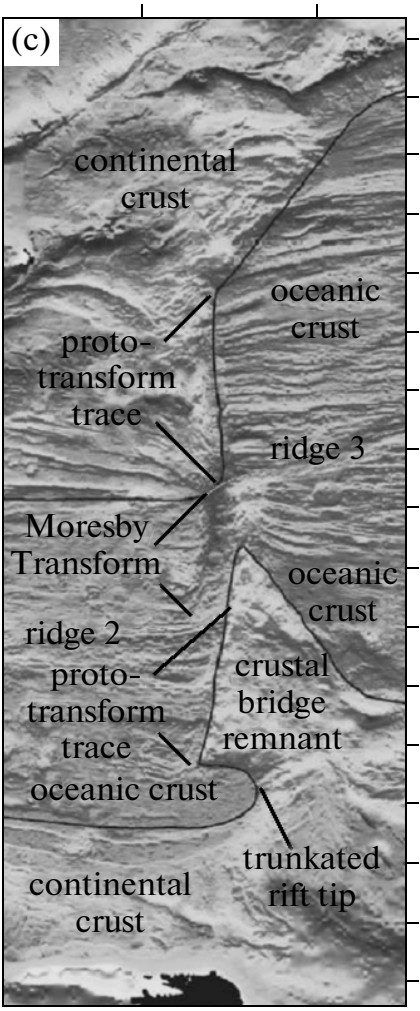

154

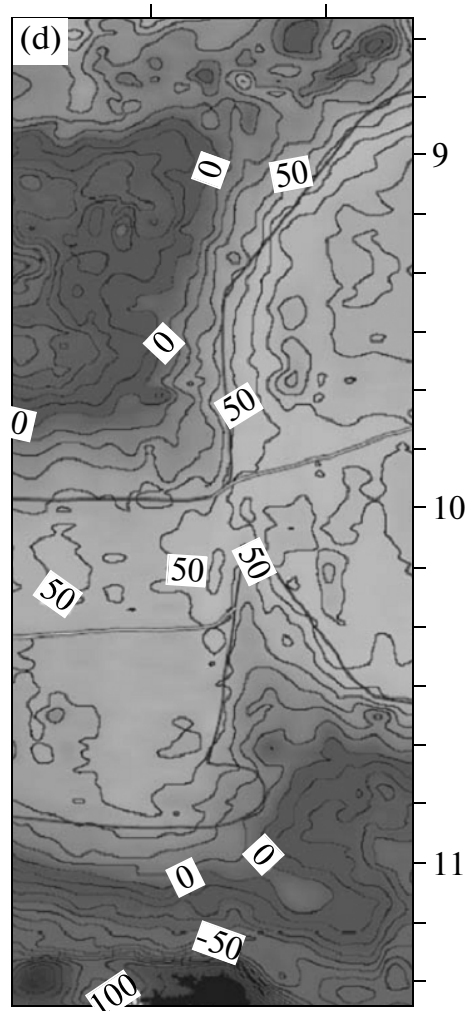

Fig. 7. Concept of development (a) and natural data (b) -(d) for the incipient spreading in the Woodlark Basin in the region of the Moresby Transform and its conjugate margins (modified after Taylor et al., 2009). (a) Generalized evolutionary model of a transform fault and fracture zone whose traces do not extend into the continental margin (white region): (1) a propagating spreading segment (grey) overlaps with an offset region of focused rifting (barbed lines); (2) the overlap continues after a spreading center nucleates within the rift basin, future proto-transform fault position is shown by the dashed line; (3) a transform fault develops by cutting through stretched continental crust bridge to link the two spreading segments, truncating the former tip of one segment. (b) Magnetization (with lineations labeled for Brunhes (B), Jaramillo (J), anomaly 2 and 2A). (c) Sunlit bathymetry (with spreading segments 2 and 3 labeled). (d) Bouguer gravity (contoured every $10 \mathrm{mGal}$ and labeled every $50 \mathrm{mGal}$ ). Black line in (b)-(d) shows continent-ocean boundary.

(5-8 Myr, Figs. 3e, 4e, 5e, 6e) is associated with the formation of two inactive fracture zones at around 5.5 Myr (Fig. 3e) and establishment of the typical mature nearly orthogonal ridge-transform pattern at around 6.5 Myr (Figs. 3e, 4e). Degree of melt extraction in the mantle increases with decreasing depth and varies from $13 \mathrm{vol} \%$ at $45 \mathrm{~km}$ depth to $26 \%$ at $10 \mathrm{~km}$ depth directly below the magma region (Fig. 6).

\section{COMPARISON WITH THE WOODLARK BASIN}

Figure 7 shows example of Moresby Transform development during initiation of the oceanic spreading in the Woodlark Basin (Taylor et al., 2009). As can be seen from this figure the interpreted development of this fault closely matches predictions from the numerical model (cf. Fig. 7 and Figs. 3-5). Similarly to the model, the Moresby (proto-) Transform fault is char- acterized by notable topographic depression and terminates in the oceanic crust (Moresby Transform, Fig. 7c). This fault formed on the timescale of around 0.5-2 Myr while linking two offset spreading segments initiated inside rift sections (Taylor et al., 2009). Our numerical models reproduces characteristic "rounded" contours of two spreading centers as well as the presence of an elongated remnant of the broken continental crustal bridge observed in the Woodlark Basin (cf. Figs. $7 \mathrm{a}-7 \mathrm{~d}$ and $3 \mathrm{~d}, 5 \mathrm{~d}$ ). When an inclined prototransform fault cuts the crustal bridge (Figs. 3c-3d, $4 c-4 d, 5 c-5 d)$, its rigid walls control the propagation of offset oceanic spreading centers toward each other (Figs. 3c-3d, 5c-5d). Proto-transform fault will thus leave traces on two opposite curved boundaries between the oceanic and continental domains (Figs. 3d, 5d). Proto-transform fault traces and truncated tips of overlapping spreading centers present in models (Figs. 3d, 5d) are also documented in nature 
(Fig. 7c). Proto-transform fault in the model started from the very tip of the early developed spreading center B and cut off significant portion $(20 \mathrm{~km})$ of the frontal part of spreading center A (Figs. 3c, 3d, 4c). This is very similar to the situation in the Woodlark Basin where the Moresby (proto)-Transform started from the tip of the early developed eastern spreading center and cut off $20 \mathrm{~km}$ long segment from the frontal part of the western spreading center (Figs. 7a, 7c). It should be mentioned, however, that the model presented here assumes laterally homogeneous spreading rate and results in nearly synchronous opening of two ridge sections. In contrast, in the Woodlark Basin, the eastern section of the ridge started to form notably before the western section did (Taylor et al., 2009, see anomalies 2A present east of the Moresby Transform only in Fig. 7b). Nevertheless, the first order dynamics of the crustal bridge and the Moresby (proto-) Transform formation should be properly captured in the model since this fault started to develop at a stage when both incipient ridge sections were simultaneously active (Fig. 7a) (Taylor et al., 2009).

\section{DISCUSSION AND CONCLUSIONS}

Inheritance of oceanic transform faults from the continental breakup stage is commonly suggested based on natural observations (e.g., Wilson, 1965; Lister et al., 1986; Cochran and Martinez, 1988; McClay and Khalil, 1998). This view is, in particular, based on a geometric correspondence between passive margins and mid-ocean ridges, which is especially prominent for the South Atlantic Ridge and the West African coast. This view is further supported by geological and geophysical data showing that stepping half-grabens (Cochran and Martinez, 1988; McClay and Khalil, 1998), segmented gravity and magnetic anomalies (Behn and Lin, 2000), or segmented weak regions (Watts and Stewart, 1998) along passive margins lead to the formation of transform faults. One of the popular conceptual models of ridge-transform patter formation (Lister et al., 1986) suggests that passive margins are characterized by an orthogonal set of normal and transfer faults; the latter can develop into transform faults. This concept has been challenged by several workers (Bosworth, 1986; Taylor et al., 1995, 2009) who presented a number of observations suggesting that the characteristic orthogonal ridge-transform fault pattern is not directly inherited from the earlier rift geometry and one-to-one correspondence between the transfer faults in the continental rift stage and transform faults in the oceanic spreading stage does not exist (Bosworth, 1986; Taylor et al., 1995, 2009). Bosworth (1986) and Rosendahl (1987), amongst others, proposed that half grabens, delimited along strike by oblique accommodation zones, are the fundamental units of rift architecture, which is gener- ally dissimilar to the orthogonal ridge-transform patterns. Also, recent high-resolution bathymetry data from the incipient oceanic spreading regions such as Woodlark Basin, Gulf of Aden and NW Australia show that spreading segments nucleate en echelon in overlapping rift basins and that initial spreading offsets, where present, are often non-transform (Taylor et al., 1995, 2009). Based on these data Taylor et al. (1995, 2009) proposed that transform faults develop rather late in the history of transition from the continental rifting to the oceanic spreading. According to the concept of Taylor et al. (2009) (Fig. 7a), transform faults develop as or after offset oceanic spreading centers nucleate in the continental rifting zone. Nucleation of transform faults is driven by the process of linking of two offset oceanic spreading segments by an extension-parallel strike-slip fault (Taylor et al., 2009) (Fig. 7a).

Results of our numerical modeling work are in the good agreement with the concept of Taylor et al. (2009) (cf. Fig. 7a and Figs. 3-5) suggesting that transform faults are not directly inherited from the early rift structures. These experiments also allow refining the Taylor's et al. (2009) concept in that a (proto)-transform fault linking two spreading segments may also initiate as an oblique (rather than only spreading-parallel, Fig. 7a) strike-slip fault. Subsequent rotation of this fault toward the extension parallel direction (Figs. 3c-3e, 4c-4e) is governed by space accommodation during continued crustal growth in two offset spreading segments linked by a sustaining weak proto-transform (Gerya, 2013). On the other hand, our model does not explain development of very large-offset transforms (up to $900 \mathrm{~km}$ ) present, for example, in the South Atlantic Ridge (e.g., Sandwell, 1986; Stoddard and Stein, 1988). Explanation for the origin of these enigmatic structures remains challenging and could possibly be related to the presence of large lithospheric-scale heterogeneities inside crustal and/or mantle portions of breaking continental plates, which could be inherited by very long proto-transform strike-slip faults.

In conclusion, our numerical model predicts that ridge-transform spreading pattern initiate in several subsequent stages: crustal rifting $(0-1.5 \mathrm{Myr})$, spreading centers nucleation and propagation (1.5-3 Myr), prototransform fault initiation and rotation (3-5 Myr) and mature ridge-transform spreading ( $>5 \mathrm{Myr}$ ). Comparison of modeling results with the natural data from the Woodlark Basin suggests that the development of this region closely matches numerical predictions.

\section{ACKNOWLEDGMENTS}

This work was supported by ETH Research Grants ETH-0807-2, ETH-0807-3, ETH-0609-2, SNF

$$
\text { PETROLOGY Vol. } 21 \quad \text { No. } 6 \quad 2013
$$


Research Grants 200020-126832, 200020-129487, SNF ProDoc program 4-D-Adamello, TopoEurope Program and Crystal2Plate program.

\section{REFERENCES}

Allken, V., Huismans, R.S., and Thieulot, C., Threedimensional numerical modeling of upper crustal extensional systems, J. Geophys. Res., 2011, vol. 116, B10409.

Allken, V., Huismans, R.S., and Thieulot, C., 2012. Factors controlling the mode of rift interaction in brittle-ductile coupled systems: a 3D numerical study, Geochem. Geophys. Geosyst., 2012, vol. 13, Q05010.

Behn, M.D. and Lin, J., Segmentation in gravity and magnetic anomalies along the U.S. east coast passive margin: implications for incipient structure of the oceanic lithosphere, J. Geophys. Res., 2000, vol. 105, pp. 25769-25790.

Behn, M.D., Lin, J., Zuber, M.T., Evidence for weak transform faults. Geophys. Res. Lett., 2002, vol. 29, doi:10.1029/2002GL015612.

Bosworth, W., Comment on detachment faulting and the evolution of passive continental margins, Geology, 1986, vol. 14, pp. 890-891.

Buck, W. R., Lavier, L. L., and Poliakov, A. N. B., Modes of faulting at mid-ocean ridges, Nature, 2005, vol. 434, pp. 719-723.

Choi, E., Lavier, L., and Gurnis, M., Thermomechanics of mid-ocean ridge segmentation, Phys. Earth Planet. Int., 2008, vol. 171, pp. 374-386.

Clauser C. and Huenges, E., Thermal conductivity of rocks and minerals, in Rock Physics and Phase Relations, Ahrens, T. J., Ed., AGU Reference Shelf, 1995, vol. 3, pp. 105-126.

Cochran, J.R. and Martinez, F., Evidence from the northern Red Sea on the transition from continental to oceanic rifting, Tectonophys., 1988, vol. 153, pp. 25-53.

Crameri, F., Schmeling, H., Golabek, G.J., Duretz, T., Orendt, R., Buiter, S.J.H., May, D.A., Kaus, B.J.P., Gerya, T.V., and Tackley, P.J., A comparison of numerical surface topography calculations in geodynamic modelling: an evaluation of the 'sticky air' method, Geophys. J. Int., 2012, vol. 189, pp. 38-54.

Dauteuil, O. and Brun, J.-P., Oblique rifting in a slowspreading ridge, Nature, 1993, vol. 361, 145-148.

Dauteuil, O., Bourgeois, O., and Mauduit, T., Lithosphere strength controls oceanic transform zone structure: Insights from analogue models, Geophys. J. Int., 2002, vol. 150, pp. 706-714.

Gerya, T., Dynamical instability produces transform faults at mid-ocean ridges, Science, 2010a, vol. 329, pp. 10471050.

Gerya, T. V., Introduction to Numerical Geodynamic Modelling (Cambridge University Press, Cambridge, 2010b.).

Gerya, T., Origin and models of oceanic transform faults, Tectonophys., 2012, vol. 522-523, pp. 34-56.

Gerya, T.V., Three-dimensional thermomechanical modeling of oceanic spreading initiation and evolution, Phys. Earth Planet. Int., 2013, vol. 214, pp. 35-52

Gregg, P. M., Behn, M. D., Lin, J., and Grove, T. L., Melt generation, crystallization, and extraction beneath segmented oceanic transform faults, J. Geophys. Res., 2009, vol. 114, B11102.
Hess, P.C., Origin of Igneous Rocks (Harward University Press, London, 1989).

Hieronymus, C.F., Control on seafloor spreading geometries by stress- and strain-induced lithospheric weakening, Earth Planet. Sci. Lett., 2004, vol. 222, 177-189.

Huismans, R.S. and Beaumont, C., Asymmetric lithospheric extension: The role of frictional plastic strain softening inferred from numerical experiments, Geology, 2002, vol. 30, pp. 211-214.

Jarrige, J.J., Ott d'Estevou, P., Burollet, P.F., Montenar, C., Richert, J.P., and Thiriet, J.P., The multistage tectonic evolution of the Gulf of Suez and northern Red Sea continental rift from field observations, Tectonics, 1990, vol. 9, pp. 441465.

Katz, R.F., Porosity-driven convection and asymmetry beneath mid-ocean ridges, Geochem. Geophys. Geosyst., 2010, vol. 11, Q0AC07.

Katz, R.F., Spiegelman, M., Langmuir, C.H., A new parameterization of hydrous mantle melting, Geochem. Geophys. Geosystems, 2003, vol. 4, 1073.

Katz, R.F., Ragnarsson, R., and Bodenschatz, E., Tectonic microplates in a wax model of sea-floor spreading, New $J$. Phys., 2005, vol. 7, doi:10.1088/1367-2630/7/1/037.

Lavier, L.L., Buck, W.R., and Poliakov, A.N.B., Factors controlling normal fault offset in an ideal brittle layer, J. Geophys. Res., 2000, vol. 105, pp. 23431-23442.

Lister, G.S., Etheridge, M.A., and Symonds, P.A., Detachment faulting and the evolution of passive continental margins, Geology, 1986, vol. 14, pp. 246-250.

Marques, F.O., Cobbold, P.R., and Lourenço, N., Physical models of rifting and transform faulting, due to ridge push in a wedge-shaped oceanic lithosphere, Tectonophys., 2007, vol. 443 , pp. $37-52$.

McClay, K. and Khalil, S., Extensional hard linkages, eastern Gulf of Suez, Egypt. Geology, 1998, vol. 6, pp. 563-566.

Montesi, L.G.J., Behn, M.D., Hebert, L.B., Lin, J., and Barry, J.L., Controls on melt migration and extraction at the ultraslow Southwest Indian Ridge $10^{\circ}-16^{\circ}$ E, J. Geophys. Res., 2011, vol. 116, B10102.

O'Bryan, J.W., Cohen, R., and Gilliland, W.N., Experimental origin of transform faults and straight spreadingcenter segments, Geol. Soc. Am. Bull., 86, 1975, 793-796.

Oldenburg, D.W. and Brune, J.N., Ridge transform fault spreading pattern in freezing wax, Science, 1972, vol. 178, pp. 301-304.

Olive, J.-A., Behn, M.D., Tucholke, B.E., The structure of oceanic core complexes controlled by the depth distribution of magma emplacement, Nature Geoscience, 2010, vol. 3, pp. 491-495.

Ragnarsson, R., Ford, J.L., Santangelo, C.D., and Bodenschatz, E., Rifts in spreading wax layers, Phys. Rev. Lett., 1996, vol. 76, pp. 3456-3459.

Ranalli, G., Rheology of the Earth, London: Chapman \& Hall, 1995.

Rosendahl, B.R., Architecture of continental rifts with special reference to East Africa, Ann. Rev. Earth Planet. Sci. Lett., 1987, vol. 15, pp. 445-503.

Sandwell, D., Thermal stress and the spacings of transform faults, J. Geophys. Res., 1986, vol. 91, pp. 6405-6417.

Schmeling, H., Babeyko, A.Y., Enns, A., Faccenna, C., Funiciello, F., Gerya, T., Golabek, G.J., Grigull, S., 
Kaus, B.J.P., Morra, G., Schmalholz, S.M., and van Hunen, J., Benchmark comparison of spontaneous subduction models - towards a free surface, Phys. Earth Planet. Int., 2008, vol. 171, pp. 198-223.

Stoddard, P.R. and Stein. S., A kinematic model of ridgetransform geometry evolution, Mar. Geophys. Res., 1988, vol. 10, pp. 181-190.

Taylor, B., Goodliffe, A., Martinez, F., and Hey, R.N., Continental rifting and initial seafloor spreading in the Woodlark Basin, Nature, 1995, vol. 374, pp. 534-537.

Taylor, B., Goodliffe, A., and Martinez, F., Initiation of transform faults at rifted continental margins, Comptes Rendus Geoscience, 2009, vol. 341, pp. 428-438.

Theissen-Krah, S., Iyer, K., Rüpke, L.H., and Phipps Morgan, J., Coupled mechanical and hydrothermal modeling of crustal accretion at intermediate to fast spreading ridges, Earth Planet. Sci. Lett., 2011, vol. 311, pp. 275-286.

Tentler, T. and Acocella, V., How does the initial configuration of oceanic ridge segments affect their interaction? Insights from analogue models, J. Geophys. Res., 2010, vol. 115, B01401.

Wanless, V.D. and Shaw, A.M., Lower crustal crystallization and melt evolution at mid-ocean ridges, Nature Geoscience, 2012, vol. 5, 651-655.

Watts, A.B. and Stewart, J., Gravity anomalies and segmentation of the continental margin offshore West Africa, Earth Planet. Sci. Lett., 1998, vol. 156, pp. 239-252.

Wilson, J.T., A new class of faults and their bearing on continental drift, Nature, 1965, vol. 207, pp. 343-347. 